\title{
Penentuan Kerugian Tahunan Dengan Pemodelan Kebencanaan Alam dan Premi Asuransi Pada Kerusakan Rumah Akibat Banjir
}

\author{
Renata P Plate ${ }^{1}$, Firdaniza $^{2}$, Dwi Susanti ${ }^{3}$ \\ ${ }^{1}$ Departemen Matematika Fakultas Matematika dan Ilmu Pengetahuan Alam \\ Universitas Padjadjaran, platephilipa@gmail.com
}

\begin{abstract}
Abstrak
Kerusakan bangunan rumah akibat banjir di kawasan sekitar daerah aliran sungai dapat menimbulkan sejumlah kerugian tahunan. Dibutuhkan jaminan asuransi untuk proteksi finansial bagi kerugian tahunan yang terjadi. Ketika suatu rumah telah diasuransikan, maka perusahaan asuransi wajib menentukan premi asuransi untuk produk asuransi tersebut. Pada paper ini dihitung kerugian tahunan dari kerusakan rumah dengan pemodelan kebencanaan alam, dan premi asuransi kerusakan rumah dengan prinsip ekivalen. Dengan menggunakan data debit air sungai Curug Agung, Subang, mulai Januari 2009 hingga Desember 2013, asumsi harga rumah Rp 150 juta, tingkat bunga 5\% dan periode asuransi 10 tahun diperoleh kerugian tahunan Rp15.154.000.00 dan premi asuransi Rp7.284.000.00.

Kata kunci: Kerusakan rumah, kerugian tahunan, premi asuransi, pemodelan kebencanaan alam, dan prinsip ekivalen
\end{abstract}

\begin{abstract}
House damage caused by flood in the area around the river stream can cause an annual loss. Insurance coverage is required for financial protection for annual losses incurred. When a house is insured, the insurance company is required to determine the insurance premium for the insurance product. The annual loss of damage to house can be determined with natural catastrophe modeling, and insurance premiums from damage to house can be determined by equivalent principle. Based on data of Curug Agungs river waterfall in Subang, from January 2009 to December 2013, house price Rp 150 million, interest rate 5\% and 10 years insurance period will obtain annual loss $R p$ Rp15.154.000,00 with natural catastrophe modeling and insurance premium $R p \% .284 .000,00$ with the equivalent principle.
\end{abstract}

Keywords: House damage caused by flood, annual loss, insurance premium, natural catastrophe modeling, and equivalent principle.

\section{Latar Belakang Masalah}

Provinsi Jawa Barat merupakan salah satu provinsi di Indonesia yang paling sering dilanda banjir [3]. Fenomena banjir di Jawa Barat tidak terlepas dari keberadaan sungai Citarum yang merupakan sungai terbesar dan terpanjang di Jawa barat. Hal tersebut menyebabkan

2000 Mathematics Subject Classification: 62P20, 91B30

Submitted: 08-07-2019, Revision: 11-01-2020, Accepted: 30-01-2020. 
peluang kerusakan akibat banjir sangat besar di kawasan sekitar DAS (Daerah Aliran Sungai) Citarum.

Kerusakan yang disebabkan oleh banjir dapat berupa kerusakan fisik pada bangunan perumahan. Perbaikan kerusakan rumah tentu membutuhkan sejumlah biaya, sehingga kerusakan rumah yang terjadi di anggap sebagai suatu kerugian. Oleh karena itu, pemilik rumah disarankan untuk memiliki jaminan suransi umum sebagai bentuk proteksi finansial. Saat suatu bangunan rumah telah diasuransikan, maka perusahaan asuransi akan menentukan kerugian tahunan dan premi asuransi dari kerusakan rumah akibat banjir. Dalam Paleasari,S, 2018, dikatakan bahwa pemerintah dan program asuransi memiliki keuntungan meningkatkan alokasi sumberdaya keuangan yang efisien dalam manajemen risiko [8].

Salah satu cara yang dapat digunakan dalam menentukan kerugian adalah dengan pemodelan kebencanaan alam, yang bertujuan membantu perusahaan asuransi dalam menyediakan persiapan dana untuk menghadapi dampak bencana alam [1]. Winspear et all, (2012) telah melakukan penelitian tentang penanggulangan dampak gempa bumi bagi risiko keuangan menggunakan pemodelam kebencanaan alam di beberapa negara berkembang di kawasan Asia [14]. Rara, et all (2014), mengunakan pemodelan kebencanaan untuk meneliti dampak finansial dari Tsunami yang terjadi di Chili [9]. Selanjutnya Sharma (2014) menggunakan pemodelan kebencanaan dalam penentuan harga asuransi pada bencana badai di Estonia [12]. Setelah nilai kerugian diketahui, maka perlu dihitung nilai premi asuransi. Menghitung premi asuransi dapat menggunakan prinsip ekivalen, yaitu ekspektasi dari kerugian asuransi adalah nol [4]. Beberapa penelitian telah menggunakan prinsip ekivalen dalam menentukan premi asuransi, seperti Anderson dan Goodchild, 2011, dalam hal premi asuransi karena penyebab alami [2], dan Furhaupter dan Bretchtmann, 2013 dalam hal premi asuransi kesehatan.

Anderson dan Goodchild, 2011 menentukan premi asurasi bencana karena penyebab alami dengan prinsip ekivalen [2], sementara Furhaupter dan Bretchtmann, 2013 menggunakan prinsip ekivelen dalam perhitungan premi asuransi kesehatan [?]. Berdasarkan uraian tersebut, maka penelitian ini membahas tentang penentuan kerugian tahunan dari kerusakan rumah akibat banjir dengan menggunakan pemodelan kebencanaan alam, dan penentuan premi asuransi dari kerusakan rumah akibat banjir dengan prinsip ekivalen. Studi kasus dilakukan di kawasan sekitar DAS Curug Agung, dimana sungai Curug Agung merupakan anak sungai dari sungai Citarum.

\section{OBJEK DAN METODE PENELITIAN}

2.1. Objek Penelitian. Objek dari penelitian ini adalah perhitungan kerugian tahunan dan premi asuransi dari kerusakan rumah akibat banjir, berdasarkan data perbulan debit air sungai Curug Agung dari 1 Januari 2009 hingga 31 December 2013 yang diperoleh dari Balai Besar Wilayah Sungai (BBWS) Citarum.

Asuransi adalah perjanjian antara dua pihak, yaitu perusahaan asuransi dan pemegang polis, yang menjadi dasar penerimaan premi oleh perusahaan asuransi sebagai imbalan [11].

2.2. Metode Penelitian. Metode penelitian ini dibagi dalam dua tahapan, tahap pertama adalah mencari kerugian tahunan dari kerusakan rumah akibat banjir dengan pemodelan kebencanaan alam, dan tahap kedua adalah mencari premi asuransi dari kerusakan rumah akibat banjir dengan prinsip ekivalen.

2.2.1. Pemodelan Kebencanaan Alam. Algoritma pemodelan kebencanaan alam terdiri dari tiga tahapan yaitu tahap bencana, tahap kerentanan dan tahap finansial [12]. Berikut ini adalah rincian tahapan-tahapan untuk mencari kerugian dari kerusakan rumah akibat banjir dengan menggunakan pemodelan kebencanaan alam

(1) Pada tahap bencana langkah-langkah yang akan dilakukan adalah

a. Asumsikan debit air Sungai Curug Agung $R \sim \operatorname{Gamma}(\rho, \sigma)$, asumsi ini didukung oleh penelitian (Singh, 1998) yang menyatakan bahwa distribusi gamma merupakan distribusi umum bagi analisis kejadian hidrologi. 
b. Tentukan nilai parameter $\rho$ dan $\sigma$ dengan metode momen (metode momen ini lebih sederhana dibanding MLE).

c. Uji asumsi $R \sim \operatorname{Gamma}(\rho, \sigma)$ dengan uji Kolmogorov-Smirnov. Untuk besar sampel $n_{R}$, pengujian dilakukan dengan terlebih dahulu menghitung nilai statistik uji $D_{n_{R}}$ dan konstanta uji $d_{n_{R}}$. Apabila $F_{n_{R}}(r)$ merupakan distribusi empiris dari $R$ dan $F(r)$ merupakan asumsi distribusi dari $R$, maka statistik uji didefinisikan sebagai

$$
D_{n_{R}}=\max \left|F_{n_{R}}(r)-F(r)\right|
$$

Selanjutnya, jika $\alpha$ merupakan tingkat kepercayaan dari pengujian, maka nilai konstanta uji adalah

$$
d_{n_{R}} \sqrt{-\frac{1}{2 n} \ln \left(\frac{\alpha}{2}\right)}
$$

d. Apabila asumsi $R \sim \operatorname{Gamma}(\rho, \sigma)$ diterima, maka tentukan fkp dari $R \sim \operatorname{Gamma}(\rho, \sigma)$ yaitu $f_{R}(r)$

e. Tentukan debit air penyebab banjir $r_{b a n}$. Debit air penyebab banjir adalah debit air yang berada di atas rata rata debit air (Badan Nasional Penanggulang bencana). Berdasarkan definisi tersebut maka diperoleh

$$
r_{\text {ban }}=r, \forall r>\rho \sigma
$$

f. Asumsikan debit air penyebab banjir $R_{b a n} \sim \operatorname{Gamma}(\lambda, \omega)$

g. Tentukan nilai parameter $\lambda$ dan $\omega$ dengan metode momen

h. Uji asumsi $R_{\text {ban }} \sim \operatorname{Gamma}(\lambda, \omega)$ dengan uji Kolmogorv-Smirnov [?]

i. Apabila asumsi $R_{\text {ban }} \sim \operatorname{Gamma}(\lambda, \omega)$ diterima, maka tentukan fkp dari $R_{\text {ban }} \sim \operatorname{Gamma}(\lambda, \omega)$ yaitu $f_{R b a n}\left(r_{\text {ban }}\right)$

(2) Pada tahap kerentanan langkah langkah yang akan dilakukan adalah

a. Tentukan biaya perbaikan kerusakan rumah akibat debit air penyebab banjir $r_{b a n}$, yaitu $g\left(r_{b a n}\right)$, dimana

$$
g\left(r_{b a n}\right)=\frac{b^{r_{b a n}}-1}{b-1}, b>1
$$

dengan $b$ adalah konstanta dan $r_{b a n \max }$ adalah nilai maksimum dari debit air penyebab banjir [7]

b. Tentukan nilai parameter $b$ dari biaya perbaikan kerusakan rumah akibat banjir dengan metode Newton Rapshon [6], informasi yang dapat digunakan adalah nilai maksimum dari debit air $r_{\text {ban max }}$ dan harga rumah $g\left(r_{\text {ban } \max }\right)$

c. Tentukan rasio kerusakan rumah akibat nilai debit air penyebab banjir $D R\left(r_{b a n}\right)$ dimana

$$
D\left(r_{\text {ban }}\right)=\frac{g\left(r_{\text {ban }}\right)}{g\left(r_{\text {ban } \max }\right)}=\frac{b^{r_{\text {ban }}}-1}{b_{\text {ban } \max }^{r}-1}
$$

d. Tentukan rata rata rasio kerusakan rumah akibat debit air penyebab banjir $M D R\left(r_{b a n_{j}}\right)$ dimana $j=1,2,3$, dots, $n$

$$
M D R\left(r_{b a n_{j}}\right)=E\left(D\left(R_{b a n}\right)\right), 0<r_{b a n} \leq r_{b a n_{j}}
$$

(3) Pada tahap finansial langkah langkah yang akan dilakukan adalah

a. Tentukan kerugian dari kerusakan rumah akibat banjir debit air penyebab banjir $l_{j}$ dimana $j=1,2,3, \ldots, n$

$$
l_{j}=M D R\left(r_{b_{a n_{j}}}\right) g\left(r_{\text {ban } \max }\right), 0<r_{\text {ban }} \leq r_{\text {ban }_{j}}
$$

b. Asumsikan kerugian dari kerusakan rumah akibat debit air penyebab banjir $L \sim$ $\operatorname{Gamma}(\theta, \delta)$

c. Tentukan nilai parameter $\theta$ dan $\delta$ dengan metode momen

d. Uji asumsi $L \sim \operatorname{Gamma}(\theta, \delta)$ dengan uji Kolmogorov-Smirnov 
e. Apabila asumsi $L \sim \operatorname{Gamma}(\theta, \delta)$ diterima, maka tentukan kerugian tahunan dari kerusakan rumah akibat banjir $A A L$

$$
A A L=\theta \delta
$$

2.2.2. Perhitungan Premi Asuransi. Dalam penelitian ini penentuan premi asuransi dilakukan dengan menggunakan prinsip ekivalen dan produk asuransi yang digunakan adalah asuransi berjangka. Tahapan-tahapan penentuan premi tersebut adalah sebagai berikut

(1) Tentukan probabilitas selang waktu diskrit antara waktu penerbitan asuransi dengan waktu terjadinya kerusakan rumah akibat debit air penyebab banjir yaitu $T(X)$ dimana

$$
\operatorname{Pr}(T(X)=t)=\left(\int_{\rho \sigma}^{\infty} f_{R}(r) d r\right)^{t-1}\left(1-\int_{\rho \sigma}^{\infty} f_{R}(r) d r\right)
$$

(2) Jika $A A L$ dianggap sebagai manfaat asuransi yang akan diterima apabila terjadi kerusakan, maka tentukan fungsi manfaat $z_{T(X)}$ yaitu

$$
z_{T(X)}=A A L(1+i)^{-T(X)}
$$

dimana $i$ adalah suku bunga

(3) Jika $P$ adalah premi asuransi yang dibayarkan disetiap awal tahun, mulai dari tahun penerbitan hingga tahun kerusakan, maka tentukan fungsi anuitas premi $P Y$ yaitu

$$
P Y=P a_{\overline{T(X)} i}
$$

(4) Tentukan nilai aktuaria sekarang fungsi manfaat $A_{x: \bar{m}}$ yaitu

$$
A_{x: \bar{m}}=E\left(z_{T(X)}\right)=\sum_{t=1}^{m} A A L(1+i)^{-t}(T(X)=t)
$$

(5) Tentukan nilai aktuaria sekarang fungsi anuitas premi yaitu $a_{x: \bar{m}}$

$$
\ddot{a}_{x: \bar{m}}=E(P Y)=\sum_{t=1}^{m} P a_{\bar{t} i} \operatorname{Pr}(T(X)=t)
$$

(6) Tentukan premi asuransi $P$ dengan menggunakan prinsip ekivalen dimana

$$
P=\frac{\sum_{t=1}^{m} A A L(1+i)^{-t}(T(X)=t)}{\sum_{t=1}^{m} P a_{\overline{t i}} \operatorname{Pr}(T(X)=t)}
$$

\section{HASIL DAN PEMBAHASAN}

3.1. Bangunan Perumahan dan Informasi Dasar. Bangunan perumahan di kawasan sekitar DAS Curug Agung memiliki potensi besar untuk mengalami kerusakan akibat banjir. Kerusakan menyebabkan munculnya kerugian, oleh sebab itu dibutuhkan jaminan asuransi untuk menanggulangi kerugian yang ada. Saat suatu rumah telah diasuransikan, perusahaan asuransi wajib menentukan kerugian tahunan dan premi asuransinya. Untuk itu, dalam penelitian ini kerugian tahunan ditentukan menggunakan pemodelan kebencanaan alam, dan premi asuransi ditentukan menggunakan prinsip ekivalen

\subsection{Pemodelan Kebencanaan Alam dari Kerusakan Rumah Akibat Banjir di Kawasan Sekitar DAS Curug Agung.}


3.2.1. Tahap Bencana dari Kerusakan Rumah Akibat Banjir di Kawasan Sekitar DAS Curug Agung. Misalkan $R \sim \operatorname{Gamma}(\rho, \sigma)$ merupakan variabel acak yang menyatakan debit air sungai Curug Agung, maka dengan menggunakan metode momen akan diperoleh $\rho=5,974$ dan $\sigma=1,837$. Jika asumsi $R \sim \operatorname{Gamma}(5,947 ; 1,837)$ diuji dengan menggunakan uji KolmogorovSmirnov, didapat statistik uji $D_{60}=0,107$ dan konstanta uji $d_{60}=0,107$, karena $d_{60}>D_{60}$ maka asumsi $R \sim \operatorname{Gamma}(5,974 ; 1,837)$ diterima. Karena asumsi $R \sim \operatorname{Gamma}(5,974 ; 1,837)$ diterima maka fkp dari $R$ adalah

$$
f_{R}(r)= \begin{cases}\frac{1}{\Gamma(5,947) 1,837^{5,947}} r^{5,947-1} e^{\frac{-r}{1,837}}, & r>0 \\ 0, & r \leq 0\end{cases}
$$

dan rata rata debit air Sungai Curug Agung adalah

$$
\rho \sigma=10,971
$$

Berdasarkan persamaan (3) maka debit air penyebab banjir adalah semua data debit air penyebab banjir sungai Curug Agung yang berada di atas $\rho \sigma=10,971$, sehingga diperoleh data debit air sungai Curug Agung seperti yang ditunjukkan oleh Tabel 1.

Tabel 1. Data Debit Air Penyebab Banjir Sungai Curug Agung

\begin{tabular}{cccccc}
\hline$j$ & $r_{\text {banj }}$ & $j$ & $r_{\text {banj }}$ & $j$ & $r_{\text {banj }}$ \\
\hline 1 & 11,827 & 9 & 17,686 & 17 & 16,817 \\
2 & 11,114 & 10 & 15,859 & 18 & 17,681 \\
3 & 14,752 & 11 & 11,491 & 19 & 14,754 \\
4 & 13,648 & 12 & 21,578 & 20 & 17,342 \\
5 & 11,566 & 13 & 14,626 & 21 & 11,789 \\
6 & 15,910 & 14 & 15,463 & 22 & 12,869 \\
7 & 25,334 & 15 & 11,761 & 23 & 14,042 \\
8 & 24,631 & 16 & 11,778 & & \\
\hline
\end{tabular}


Misalkan $R_{\text {ban }} \sim \operatorname{Gamma}(\lambda, \omega)$ merupakan variabel acak yang menyatakan debit air penyebab banjir Sungai Curug Agung, maka dengan menggunakan metode momen diperoleh $\lambda=15,506$ dan $\omega=0,994$. Kemudian asumsi $R_{\text {ban }} \sim \operatorname{Gamma}(15,506 ; 0,994)$ diuji menggunakan uji Kolmogorov-Smirnov, didapat statistik uji $D_{23}=0,131$ dan konstanta uji $d_{23}=0,283$, karena $d_{23}>D_{23}$ maka asumsi $R_{\text {ban }} \sim \operatorname{Gamma}(15,506 ; 0,994)$ diterima. Karena asumsi $R_{\text {ban }} \sim \operatorname{Gamma}(15,506 ; 0,994)$ diterima maka fkp dari $R$ adalah

$$
f_{R}(r)=\left\{\frac{1}{\Gamma(15,506) 0,994^{15,506}} r^{15,506-1} e^{\frac{-r}{0,994}}\right.
$$

3.2.2. Tahap Kerentanan dari Kerusakan Rumah Akibat Banjir di Kawasan Sekitar DAS Curug Agung. Berdasarkan persamaan (4) maka diperoleh biaya perbaikan kerusakan rumah akibat debit air penyebab banjir sungai Curug Agung akibat nilai maksimum debit air sungai Curug Agung $r_{\text {ban max }}$ adalah harga rumah $g\left(r_{\text {ban } \max }\right)=25,334$ sehingga diperoleh

$$
150=\frac{b^{25,334}-1}{b-1}, b>1
$$

atau

$$
0=f(b)=b^{25,334}-150 b+149
$$

Dengan menggunakan metode Newton-Rapshon dengan tebakan awal $b_{0}=1,5$ maka diperoleh nilai $b=1,5$. Kemudian berdasarkan persamaan (6), maka diperoleh rata rata rasio kerusakan $M D R\left(r_{b a n j}\right)$, untuk $j=1,2, \ldots, n$ yaitu

$$
\operatorname{MDR}\left(r_{\text {banj }}\right)=\int_{0}^{r_{\text {banj }}} \frac{\left(1,125_{\text {ban }}^{r}-1\right) r_{\text {ban }}^{15,506-1} e^{\frac{r_{b a n}}{0,994}}}{\left(1,125^{25,334}-1\right) \Gamma(15,506) 0,994^{15,506}} d r_{b a n}
$$

Berdasarkan persamaan (20), maka diperoleh kumpulan nilai rata rata rasio kerusakan rumah akibat debit air penyebab banjir seperti yang ditunjukkan oleh Tabel 2

Tabel 2. Rata-Rata Rasio Kerusakan Rumah Akibat Debit Air Penyebab Banjir Sungai Curug Agung

\begin{tabular}{cccccc}
\hline$j$ & $r_{\text {banj }}$ & $M D R\left(r_{\text {banj }}\right)$ & $j$ & $r_{\text {banj }}$ & $M D R\left(r_{\text {banj }}\right)$ \\
\hline 1 & 11,827 & 0,023 & 13 & 14,626 & 0,077 \\
2 & 11,114 & 0,015 & 14 & 15,463 & 0,100 \\
3 & 14,752 & 0,081 & 15 & 11,761 & 0,022 \\
4 & 13,648 & 0,054 & 16 & 11,778 & 0,022 \\
5 & 11,566 & 0,018 & 17 & 16,817 & 0,139 \\
6 & 15,910 & 0,113 & 18 & 17,681 & 0,164 \\
7 & 25,334 & 0,296 & 19 & 14,754 & 0.081 \\
8 & 24,631 & 0,292 & 20 & 17,342 & 0,154 \\
9 & 17,686 & 0,164 & 21 & 11,789 & 0,022 \\
10 & 15,859 & 0,111 & 22 & 12,869 & 0,039 \\
11 & 11,491 & 0,018 & 23 & 14,042 & 0,063 \\
12 & 21,578 & 0,255 & & & \\
\hline
\end{tabular}


3.2.3. Tahap Finansial dari Kerusakan Rumah Akibat Banjir di Kawasan Sekitar DAS Curug Agung. Berdasarkan persamaan (7) maka diperoleh kerugian dari kerusakan rumah akibat debit air penyebab banjir sungai Curug Agung $l_{j}$ dimana $j=1,2, \ldots, n$

$$
l_{j}=\left(\int_{0}^{r_{\text {banj }}} \frac{\left(1,125_{\text {banj }}^{r}-1\right) r_{\text {ban }}^{15,506-1} e^{\frac{-r_{\text {ban }}}{0,994}}}{\left(1,125^{25,334}-1\right) \Gamma(15,506) 0,994^{15,506}} d r_{\text {ban }}\right) 150
$$

Berdasarkan persamaan (21) maka diperoleh kumpulan nilai kerugian dari kerusakan rumah akibat debit air penyebab banjir seperti yang ditunjukkan oleh Table 3

Tabel 3. Kerugian dari Kerusakan Rumah Akibat Debit Air Penyebab Banjir Sungai Curug Agung

\begin{tabular}{cccccc}
\hline$j$ & $\begin{array}{c}\text { Debit air penyebab } \\
\text { banjir }\left(\mathrm{dm}^{3} / \text { menit }\right)\end{array}$ & $\begin{array}{c}\text { Kerugian } \\
\text { (juta rupiah) }\end{array}$ & $j$ & $\begin{array}{c}\text { Debit air penyebab } \\
\text { banjir }\left(\mathrm{dm}^{3} / \text { menit }\right)\end{array}$ & $\begin{array}{c}\text { Kerugian } \\
\text { (juta rupiah) }\end{array}$ \\
\hline 1 & 11,827 & 3,450 & 13 & 14,626 & 11,550 \\
2 & 11,114 & 2,250 & 14 & 15,463 & 15,000 \\
3 & 14,752 & 12,150 & 15 & 11,761 & 3,300 \\
4 & 13,648 & 8,100 & 16 & 11,778 & 3,300 \\
5 & 11,566 & 2,700 & 17 & 16,817 & 20,850 \\
6 & 15,910 & 16,950 & 18 & 17,681 & 24,600 \\
7 & 25,334 & 44,400 & 19 & 14,754 & 12,150 \\
8 & 24,631 & 43,800 & 20 & 17,342 & 23,100 \\
9 & 17,686 & 24,600 & 21 & 11,789 & 3,300 \\
10 & 15,859 & 16,650 & 22 & 12,869 & 5,850 \\
11 & 11,491 & 2,700 & 23 & 14,042 & 9,450 \\
12 & 21,578 & 38,250 & & & \\
\hline
\end{tabular}

Misalkan $L \sim \operatorname{Gamma}(\theta, \delta)$ merupakan variabel acak yang menyatakan kerugian dari kerusakan rumah akibat debit air penyebab banjir sungai Curug Agung, maka dengan menggunakan metode momen akan diperoleh $\theta=1,418$ dan $\delta=10,487$. Jika asumsi $L \sim$ Gamma $(1,418 ; 10,487)$ diuji menggunakan uji Kolmogorov-Smirnov, maka didapat statistik uji $D_{23}=0,171$ dan konstanta uji $d_{23}=0,283$, karena $d_{23}>D_{23}$ maka asumsi $L \sim$ $\operatorname{Gamma}(1,418 ; 10,487)$ diterima. Karena asumsi $L \sim \operatorname{Gamma}(1,418 ; 10,487)$ diterima, maka berdasarkan persamaan (8) kerugian tahunan dari kerusakan rumah akibat banjir adalah

$$
A A L=15,154
$$

Berdasarkan persamaan (22) kerugian tahunan dari kerusakan rumah akibat banjir adalah Rp15.154.000,00

3.3. Penentuan Premi Asuransi dari Kerusakan Rumah Akibat Banjir di Kawasan Sekitar DAS Curug Agung. Jika $X$ merupakan variabel acak diskrit yang menyatakan tahun dimana rumah mengalami kerusakan akibat banjir, maka $T(X)=X-x$ merupakan variabel acak diskrit yang menyatakan selang waktu antara tahun penerbitan asuransi dengan tahun terjadinya kerusakan rumah akibat banjir. Berdasarkan persamaan (9), persamaan (15) dan nilai $\rho \sigma-10.971$, maka diperoleh fkp dari $T(X)$ yaitu

$$
\operatorname{Pr}(T(X)=t)=_{t \mid 1} q_{x}=0,559^{t-1} 0,441
$$

Produk asuransi yang dibeli pemilik rumah adalah produk asuransi berjangka dengan periode asuransi 10 tahun, tingkat bunga 5\%, manfaat asuransi sebesar nilai kerugian dari kerusakan rumah akibat banjir yaitu, dan pembayaran premi sebesar disetiap awal tahun mulai dari tahun penerbitan asuransi hingga tahun terjadinya kerusakan. Berdasarkan persamaan (10), maka diperoleh fungsi manfaat asuransi

$$
z_{T(X)}=15,154(1+5 \%)^{-T(X)}
$$


dan berdasarkan persamaan (11) diperoleh fungsi anuitas premi

$$
P Y=P a \overline{T(X)} 5 \%
$$

Sehingga, dengan mensubstitusikan persamaan (23) dan persamaan (24) ke persamaan (12) diperoleh nilai aktuaria sekarang dari fungsi manfaat

$$
A_{x: \overline{10}}=E\left(z_{T(X)}\right)=\sum_{t=1}^{10} 15,154(1+5 \%)^{-t}(0,559)^{t-1} 0,441=15,113
$$

dan dengan mensubstitusikan persamaan (23) dan persamaan (25) ke persamaan (13) diperoleh nilai aktuaria sekarang dari fungsi anuitas premi

$$
\ddot{a}_{x: \overline{10}}=E(P Y)=\sum_{t=1}^{10} P a_{\bar{t} \mid 0,05} 0,559^{t-1} 0,441=2,075 P
$$

Merujuk pada persamaan (14) tentang penentuan premi asuransi dengan menggunaan prinsip ekivalen, maka berdasarkan persamaan (26) dan (27) diperoleh nilai premi asuransi yaitu

$$
P=\frac{\sum_{t=1}^{m}}{15,154(1+5 \%)^{-t} 0,559^{t-1} 0,441} \sum_{t=1}^{m} a_{\bar{t} \mid 0,05} 0,559^{t-1} 0,441=\frac{15,113}{2,075}=7,284
$$

Berdasarkan persamaan (28) maka premi asuransi dari kerusakkan rumah akibat banjir adalah Rp7.284.000,00.

\section{Kesimpulan}

Berdasarkan penelitian terhadap bangunan rumah yang memiliki potensi kerusakan akibat banjir yang terjadi di kawasan sekitar Daerah Aliran Sungai (DAS) Curug Agung, Subang, maka dapat disimpulkan bahwa kerugian tahunan dari kerusakan rumah akibat banjir dengan menggunakan pemodelan kebencanaan alam adalah sebesar Rp15.154.000,00. Premi asuransi dari kerusakan rumah akibat banjir dengan menggunakan prinsip ekivalen adalah sebesar Rp7.284.000,00

\section{DAFtar Pustaka}

[1] Air Worldwide. 2017. Modeling Extreme Event Risk. https://www.air-worldwide.com/Models/AboutCatastrophe-Modeling/

[2] Anderson, Paul D. dan Seth A. Goodchild. 2011. Quantifying Risk Load for Property Catastrophe Exposure. Casualty Actuarial Society.

[3] Badan Nasional Penanggulangan Bencana BNPB. 2016. Data dan Informasi Bencana Indonesia. https://dibi.bnpb.go.id/data-bencana/lihat-data/

[4] Bowers, Newton L, Hans U. Greber, James C. Hickman, Donald A. Jones dan Cecil J. Nesbit. 1997. Actuarial Mathematics. The Society of Actuaries.

[5] Direktorat Jendral Rehabilitasi Lahan dan Perhutanan Sosial. 2014. Monitoring dan Evaluasi Pengelolaan Daerah Aliran Sungai. Jakarta: Departemen Kehutanan.

[6] Munir, Rinaldi. 2003. Metode Numerik. Informatika Bandung.

[7] Nhu Y.N., Ichikawa,Y. dan Ishidara,H. 2016. Establishing Flood Damage for Agricultural Crops Using Flood Disaster Statistics in Data Scarce Regions. University of Yamanashi

[8] Paleasari,S. 2018. Disaster risk insurance: A comparison of national schemes in the EU-28, International Journal of Disaster Risk Reduction Volume 35, April 2019, 101059

[9] Rara, Vaclav, Christina Arango, Peter Puncochar, Goran Trendafiloski dan Chris Ewing. 2014. A Probabilistic Tsunami Model for Chille. City College of New York.

[10] Rainer, F. and Bretchman, C. 2013. A Survey of The Private Health Insurance in Germany. Trans 27th International Conference of Actuaries

[11] Republik Indonesia. 2014. Undang-Undang No.40 tahun 2014 tentang Perasuransian. Lembaran Negara RI tahun 2014. Sekertariat Negara. Jakarta.

[12] Sharma, Kapil. 2014. Natural Catastrophe Modeling for Pricing in Insurance. University of Tartu.

[13] Singh, V.P. 1998. Entrophy-Based Parameter Estimation in Hydrologi. Springer. Dordrecht

[14] Winspear, Musuli, dan Sharma. 2012. Earthquake Catastrophe Models in Disaster Response Planning, Risk Mitigation and Financing in Developing Countries in Asia. The Geological Society of London. 